
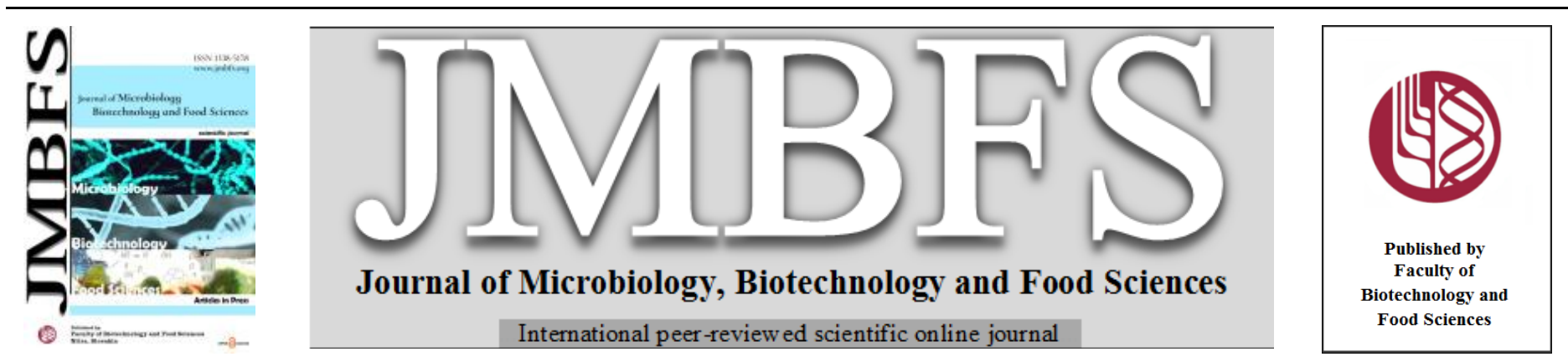

\title{
TOTAL POLYPHENOLS AND ANTIOXIDANT ACTIVITY IN SWEET POTATOES (IPOMOEA BATATAS L.) AFTER HEAT TREATMENT
}

\author{
Hana Franková*l, Marek Šnirc ${ }^{1}$, Ivona Jančo ${ }^{1}$, Natália Čeryovál, Monika Ňorbovál, Judita Lidikovál, Janette Musilovál
}

Address(es): Ing. Hana Franková,

${ }^{1}$ Slovak University of Agriculture in Nitra, Faculty of Biotechnology and Food Sciences, Institute of Food Sciences, Tr. A. Hlinku 2, 94976 Nitra, Slovakia, phone number: +42137641 4375 .

*Corresponding author: xchrkavah@uniag.sk

https://doi.org/10.55251/jmbfs.5356

\section{ARTICLE INFO}

Received 1. 10. 2021

Revised 21. 1. 2022

Accepted 26. 1.2022

Published 1. 6. 2022

Regular article

open $\partial_{\text {access }}$

\begin{abstract}
Sweet potatoes are reported to be a good source of bioactive compounds. The aim of this study was to evaluate the impact of different heat treatment methods (microwaving, steaming, and baking) and variety on the total polyphenol content and antioxidant activity of three sweet potato varieties - Beauregard (orange-fleshed), O'Henry (white-fleshed), and 414-purple (purple-fleshed). All investigated parameters were determined spectrophotometrically. The total polyphenol content was in the range of 0.53 (O'Henry) - 5.60 mg GAE.g ${ }^{1} \mathrm{DW}$ (414-purple) for raw flesh and 1.68 (O’Henry) - $7.03 \mathrm{mg} \mathrm{GAE} \cdot \mathrm{g}^{-1} \mathrm{DW}$ (414-purple) for raw peel of sweet potatoes. Heat treatments

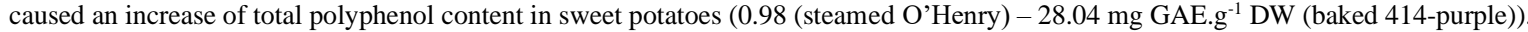
In terms of antioxidant activity, the steamed samples of variety 414-purple showed the highest values of DPPH radical scavenging activity $\left(4.51 \mu \mathrm{mol} \mathrm{TE} . \mathrm{g}^{-1} \mathrm{DW}\right)$ and Ferric reducing antioxidant power assay $\left(19.57 \mu \mathrm{mol} \mathrm{TE} . \mathrm{g}^{-1} \mathrm{DW}\right)$ compared to the other treatment methods. Spearman's test showed a strong positive relationship between both used methods for evaluation of antioxidant activity. All studied processing methods positively affected the total polyphenol content and antioxidant activity in sweet potatoes.
\end{abstract}

\section{INTRODUCTION}

Sweet potato (Ipomoea batatas L.) belongs to the most important economic crop in many Asian, African, and Latin American countries. In recent years, sweet potato has been considered a beneficial food crop worldwide due to its high nutritional potential (Guo et al., 2019). Nowadays, the cultivation of sweet potatoes is spread worldwide thanks to great adaptability to different climatic conditions. It is tolerant to relatively low temperatures in higher altitudes, but it is very sensitive to freezing temperatures (Lim, 2016). Edible roots of sweet potato are the main reason for its cultivation. Not only tuberous roots, but all parts of sweet potato, including leaves and stems, can find application in the human diet or as a feed for animals (Kwak, 2019). The edible roots are long and conically shaped with variously colored flesh and smooth skin (Jain et al., 2015). The flesh color varies from white to orange and purple. Besides the peel or flesh color, different colored varieties of sweet potatoes can also vary in their nutritional and phytochemical composition (Ayeleso et al., 2016; de Albuquerque et al., 2019). Unlike ordinary potatoes (Solanum tuberosum L.), sweet potato roots have a much better nutritional composition (de Albuquerque et al., 2019). Starch, protein, dietary fiber, vitamins, and minerals provide energy and nutrients for human health and are abundant in sweet potatoes (Sun $\boldsymbol{e t}$ al., 2019). They are also low in fat and cholesterol (Teow et al., 2007). Sweet potatoes are also characterized by a high content of bioactive compounds, such as phenolic acids, flavonoids, anthocyanins, and carotenoids. Besides their antioxidant activity, carotenoids and phenolic compounds give sweet potatoes their distinctive flesh colors (Donado-Pestana $\boldsymbol{e t}$ al., 2012; Sun et al., 2019).

The presence of bioactive compounds in sweet potato tubers is directly related to the wide spectrum of potential health benefits, such as antioxidant, immunomodulatory, antitumor, antimicrobial, antidiabetic, antiobesity, and hepatoprotective activities (Ji et al., 2015; Ayeleso et al., 2016). Polyphenols and carotenoids are among the most abundant compounds in sweet potatoes and have several benefits in the human diet (Wang et al., 2018). These compounds represent an important group of natural antioxidants (Xu et al., 2017) though, the high antioxidant activity of many foods is especially attached with the occurrence of polyphenols (Wang et al., 2018). Polyphenols represent a large class of secondary metabolites widespread in the plant kingdom. Currently, more than 8000 phenolic structures are known and, based on their chemical structure, they form 5 main classes: phenolic acids, flavonoids, stilbenes, coumarins, and tannins) (Arfaoui,
2021). The presence of many phytochemicals in sweet potatoes attracted not only the attention of researchers but also increased awareness among consumers about the nutritional value of sweet potato and its positive effect on human health (Aveleso et al., 2016; Mwanga et al., 2017).

However, the content of phenolic compounds in sweet potatoes is varietydepending. In fact, differences in composition and the content were also found in the individual morphological parts (flesh and peel) of the sweet potato root (Harrison et al., 2008). The initial content of polyphenols in foods, food matrix, as well as food processing are the most crucial factors influencing the bioavailability of polyphenols. Most fruit and vegetable are consumed processed. Industrial or domestic heat processing (e.g., boiling, baking, steaming, etc.) influence the content of polyphenols, their bioaccessibility, and bioavailability (Arfaoui, 2021).

This study was focused on the determination of the total polyphenol content and antioxidant activity in different sweet potato varieties. Since sweet potatoes are mainly consumed after heat treatment, the effect of different heat treatment methods on the polyphenol content and antioxidant activity was studied.

\section{MATERIAL AND METHODS}

\section{Chemicals}

Methanol (99.8\%), gallic acid (p.a.), DPPH (2,2'-diphenyl-1-picrylhydrazyl), Trolox (2,5,7,8-tetramethylchroman-2-carboxylic acid), TPTZ (2,4,6-tri(2pyridyl)-s-triazine), $\mathrm{HCl}$, and acetic acid, were purchased from Sigma-Aldrich (Sigma Aldrich Chemie $\mathrm{GmbH}$, Steiheim, Germany); $\mathrm{Na}_{2} \mathrm{CO}_{3}$ and $\mathrm{FeCl}_{3}$ were purchased from CentralChem (Slovakia); sodium acetate was provided by Mikrochem (Slovakia) and Folin-Ciocalteu reagent was purchased from Merck (Merck KGaA, Darmstadt, Germany).

\section{Sweet potato samples preparation}

Three sweet potato varieties - Beauregard (orange-fleshed), O'Henry (whitefleshed), and 414-purple (purple-fleshed) were used for the analyses. All cultivars were cultivated in the cadastral area of Vukovar in Eastern Croatia. Approximately $3 \mathrm{~kg}$ of sweet potato tubers from each variety were used for extract preparation (raw peel and raw flesh) and further heat processing. 
Sweet potatoes were thoroughly cleaned and washed with distilled water $\left(\mathrm{dH}_{2} \mathrm{O}\right)$. Subsequently, the tubers were peeled, and separated peel was mixed (Grindomix GM 200, Retsch, Haan, Germany; $30 \mathrm{sec}$ ) and homogenized. Peeled sweet potatoes (flesh) were washed repeatedly with $\mathrm{dH}_{2} \mathrm{O}$ and cut into slices about $3 \mathrm{~mm}$ thick. A part of the tubers thus prepared (raw flesh) was mixed (Grindomix GM 200, Retsch, Haan, Germany; $30 \mathrm{sec}$ ) and homogenized. The other three parts of the tuber were heat-treated according to methods by Musilová et al. (2020) as follows: microwaving (5 min, $800 \mathrm{~W})$, steaming $\left(15 \mathrm{~min}, 97 \pm 2{ }^{\circ} \mathrm{C}\right)$, and baking $(15 \mathrm{~min}$, $200^{\circ} \mathrm{C}$ ). After each heat treatment, slices of sweet potatoes were cooled and mixed (Grindomix GM 200, Retsch, Haan, Germany; $30 \mathrm{sec}$ ) and then homogenized. Extracts required for analysis were prepared from the homogenized samples in $80 \%$ methanol.

To prepare the extracts, $25 \mathrm{~g}$ of homogenized material (raw peel and raw, microwaved, steamed, and baked flesh, respectively) was taken and poured with $50 \mathrm{~mL} 80 \%$ methanol. The samples thus prepared were extracted for 12 hours by horizontal shaker (Heidolph Promax 1020, Heidolph Instruments $\mathrm{GmbH}$ Schwabach, Germany). The extracts were filtrated through Muktell No 392 paper (Munktell \& Filtrac GmbH, Bärenstein, Germany) and stored in closed $50 \mathrm{~mL}$ centrifuge tubes at $4{ }^{\circ} \mathrm{C}$ in the refrigerator

\section{Sample analysis}

\section{Determination of total polyphenol content}

The total polyphenol content (TPC) was determined spectrophotometrically (spectrophotometer Shimadzu UV-1800, Kyoto, Japan) using Folin-Ciocalteu agent according to the method by Lachman et al. (2006) as follows: to the aliquot volume of sample extract $(0.1 \mathrm{~mL})$ in the volumetric flask $(50 \mathrm{~mL})$, the FolinCiocalteu reagent was added. $5 \mathrm{~mL}$ of $20 \%$ sodium carbonate aqueous was added after 3 minutes, and distilled water was added to the mark. Standard solutions of gallic acid for the calibration curve were prepared by the same procedure. Prepared solutions were mixed and left at laboratory temperature for 2 hours. After that, the absorbance of solutions was measured at $765 \mathrm{~nm}$. The total content of polyphenols in samples was expressed as $\mathrm{mg}$ gallic acid equivalent per gram of dry weight ( $\mathrm{mg}$ GAE.g $\left.{ }^{-1} \mathrm{DW}\right)$.

\section{DPPH radical scavenging activity}

The method, based on scavenging the stable free radical of 2,2'-diphenyl-1picrylhydrazyl (DPPH), according to Brand-Williams et al. (1995), was used for the determination of antioxidant activity (AA). A stock solution of DPPH free radical was prepared by dissolving $0.025 \mathrm{~g}$ of DPPH in methanol (99.8\%) in a 100 $\mathrm{mL}$ flask and stored in a cold and dark place. For analysis, DPPH working solution was prepared from the DPPH stock solution by mixing with methanol (1:10). The analysis was performed as follows: the absorbance of DPPH working solution at the wavelength of $515.6 \mathrm{~nm}$ was measured $\left(\mathrm{A}_{0}\right)$ by UV-VIS spectrophotometer (Shimadzu, Kyoto, Japan). Subsequently, $0.1 \mathrm{~mL}$ of the sample extract was added to the DPPH solution in the cuvette, evenly mixed, and left to stand for 10 minutes in darkness. After that, the absorbance $\left(\mathrm{A}_{10}\right)$ was measured. Based on the values of absorbance of DPPH solution $\left(\mathrm{A}_{0}\right)$ and the absorbance at time $\mathrm{t}=10$ minutes $\left(\mathrm{A}_{10}\right)$ after adding sample extract, the percentage values of DPPH inhibition were calculated for each sample according to the formula:

$$
\text { \%DPPH inhibition }=\left[\left(\mathrm{A}_{0}-\mathrm{A}_{10}\right) / \mathrm{A}_{0}\right] \times 100 .
$$

The antioxidant activity evaluated by the DPPH method was expressed as $\mu$ mols of Trolox equivalents per gram of dry weight ( $\left.\mu \mathrm{mol} \mathrm{TE} . \mathrm{g}^{-1} \mathrm{DW}\right)$.

\section{Ferric reducing antioxidant power assay}

The ferric reducing antioxidant power (FRAP) assay was performed according to Firuzi et al. (2005).The FRAP reagent was prepared by mixing a TPTZ solution (5 mmol.L $\mathrm{L}^{-1}$ in $\left.40 \mathrm{mmol} . \mathrm{L}^{-1} \mathrm{HCl}\right)$, ferric chloride solution $\left(10 \mathrm{mmol} . \mathrm{L}^{-1}\right)$, and acetate buffer (acetic acid, $\mathrm{c}=0.1$ mol. $\mathrm{L}^{-1}$; sodium acetate, $\mathrm{c}=0.1 \mathrm{~mol} . \mathrm{L}^{-1}, \mathrm{pH} 3.6$ ) in a ratio of 1:1:10. Sample solutions for determination were prepared as follows: to $6 \mathrm{~mL}$ of FRAP reagent in test tubes, $0.1 \mathrm{~mL}$ of each sample extract was added, evenly mixed (Heidolph Reax top, Heildolph Instruments GmbH, Schwabach, Germany), and the test tubes were closed. The samples thus prepared were left in a water bath at $37^{\circ} \mathrm{C}$ in the dark for 30 minutes. Standard solutions of Trolox for the calibration curve were prepared by the same procedure as samples. After that, the absorbance at the wavelength of $593 \mathrm{~nm}$ was measured (spectrophotometer Shimadzu UV-1800, Kyoto, Japan). The ferric reducing antioxidant power was expressed as $\mu$ mols of Trolox equivalents per gram of dry weight $\left(\mu \mathrm{mol} \mathrm{TE} . \mathrm{g}^{-1}\right.$ DW).

\section{Statistical analysis}

All analyses were performed in four repetitions $(n=4)$. The results were expressed as average \pm standard deviation (SD). At first, the dataset was tested for normality. All the tested variables were distributed nonparametric. Therefore, the Kruskal-
Wallis test was used for the determination of the statistical differences $(\mathrm{p}<0.05)$ between varieties and between heat treatment methods. Spearman's correlation coefficient was used to determine the relationship between investigated parameters (TPC, DPPH, and FRAP). The computational work, including the graphical presentations, was performed using RStudio (2020) software package.

\section{RESULTS AND DISCUSSION}

\section{Total polyphenol content}

Polyphenols represent an important group of secondary plant metabolites playing various roles in plants (Manach $\boldsymbol{e t}$ al., 2004). The presence and content of polyphenols generally depend on genetics (Siracusa et al., 2014). Among sweet potato varieties, sweet potatoes with purple flesh are characterized by a high content of polyphenols (de Albuquerque et al., 2019), which was confirmed by our results (Table 1). The concentration of polyphenols compounds is not equal in all parts of sweet potatoes. More than $78 \%$ of phenolic substances are found in the peel and surrounding flesh, and their concentration decreases towards the center of the tuber (Padmaja, 2009; Jung et al., 2011; Lim, 2016). Im et al. (2021) reported higher total polyphenol content (TPC) in outer layers of purple sweet potato tubers. The total polyphenol content in investigated raw sweet potato flesh samples was

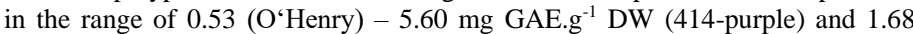

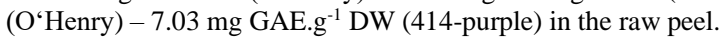

TPC in purple-fleshed variety (414-purple) was several times higher than in orange-fleshed (Beauregard) and white-fleshed (O`Henry) sweet potatoes (SP) (Table 1). Some previous studies have reported the highest content of polyphenols in purple sweet potato varieties (Kim et al., 2015; Cartier et al., 2017), which agrees with our results. Variety has the greatest influence on the content of bioactive substances in sweet potatoes (Teow et al., 2007; Rumbaoa et al., 2009). In general, purple varieties of sweet potatoes, in contrast to white, yellow, or orange-fleshed sweet potatoes, are characteristic of high polyphenol content (Oki et al., 2003; Kurata et al., 2019). Kim et al. (2015) reported from 2- to 5-times higher TPC in purple varieties than in white or orange SP varieties. These differences between varieties are affected by many factors. Genetics is one of the most significant agents playing a crucial role in the production of secondary metabolites, including phenolics, so varieties with various flesh colors have different levels of expression of phenolic compounds (Donado-Pestana et al., 2012).

Comparison with previous studies revealed differences in the measured TPC values. Higher total polyphenol content was determined in Beauregard and O'Henry from Virginia (4.30 and $2.45 \mathrm{mg} \mathrm{GAE}^{-1} \mathrm{~g}^{-1} \mathrm{DW}$, respectively) (Cartier $\boldsymbol{e}$ al., 2017). Moreover, Kourouma et al. (2020) reported higher TPC in 25 SP varieties from China with a pale yellow to orange flesh color $(3.13-9.38 \mathrm{mg}$ GAE. $\mathrm{g}^{-1} \mathrm{DW}$ ). In 8 varieties of orange sweet potatoes from Africa was measured a lower content of polyphenols than in the studies mentioned above, ranging from 1.062 to $2.432 \mathrm{mg} \mathrm{GAE}^{-1}{ }^{-1}$ DW (Koala et al., 2013). Donado-Pestana et al. (2012) reported TPC in sweet potatoes with orange flesh in the range of $1.30-1.93$ mg GAE. $\mathrm{g}^{-1} \mathrm{DW}$. These values are comparable with results in variety Beauregard (1.42 mg GAE. $\left.\mathrm{g}^{-1} \mathrm{DW}\right)$.

Due to the monitored heat treatments (microwaving, steaming, and baking), the TPC increased in the case of all varieties (Beauregard, O'Henry, and 414-purple). In heat-treated samples, TPC values ranged between 0.98 (O'Henry - steaming) and $28.04 \mathrm{mg} \mathrm{GAE}^{-1}{ }^{-1} \mathrm{DW}$ (414-purple - baking). TPC in the varieties O'Henry and 414-purple increased in order of raw flesh $<$ steaming $<$ microwaving $<$ baking. In variety Beauregard, TPC increased in the following order: raw flesh < microwaving < steaming < baking. In baked SP of all monitored varieties, the greatest increase of TPC was observed compared to raw flesh. An increase of total polyphenol content in sweet potatoes due to heat treatment has been reported in previous studies by many authors (Dincer et al., 2011; Ateea et al., 2012; Musilová et al., 2017; Nicoletto et al., 2018; Xu et al., 2018). In variety Beauregard, Ateea et al. (2012) reported the highest polyphenol content after boiling and microwaving ( 2.8 and 2.6 times higher TPC than in raw sample). In white sweet potatoes, steaming led to the highest increase of total polyphenols (Nicoletto et al., 2018). Heat treatments, such as microwaving and steaming, can cause cell structure disruption, which can result in better extraction of compounds from the cell matrix (Tian et al., 2016; Minatel et al., 2017; Nicoletto et al., 2018). On the other hand, some authors reported a decrease in TPC in sweet potatoes due to heat processing (Donado-Pestana et al., 2012; Xu et al., 2018; Kourouma et al., 2020). Xu et al. (2018) reported a decrease of TPC in heat-treated samples of Beauregard variety while, in the purple variety, there was an increase in TPC due to heat treatment (the highest increase after boiling). Purple variety was also reported to have the highest TPC in raw and all processed samples. In orangefleshed sweet potatoes from Brazil, heat-processing methods led to a significant loss of TPC. However, the phenolic compounds resisted heat treatment better than carotenoids (Donado-Pestana et al., 2012). The impact of heat treatment on TPC depends on many factors, such as variety, the temperature of heat treatment, heat treatment method, etc. (Xu et al., 2018).

Figure 1 shows the relationship between sweet potato variety and TPC. There is a very strong significant difference in TPC between sweet potato varieties $(\mathrm{p}=1.5 \mathrm{e}$ 
${ }^{08}$ ). A significantly higher content of polyphenols was found in variety 414-purple, which was confirmed by the Kruskal-Wallis test.

Table 1 Total polyphenol content and antioxidant activity in raw and heat-treated sweet potatoes

\begin{tabular}{|c|c|c|c|c|}
\hline \multirow[b]{2}{*}{ Variety } & \multirow[b]{2}{*}{ Heat treatment } & \multirow{2}{*}{$\begin{array}{c}\text { TPC } \\
\left(\mathrm{mg} \mathrm{GAE} . \mathrm{g}^{-1} \mathrm{DW}\right)\end{array}$} & \multicolumn{2}{|c|}{ Antioxidant activity } \\
\hline & & & $\begin{array}{c}\text { DPPH } \\
\left(\mu \mathrm{mol} \mathrm{TE} \cdot \mathrm{g}^{-1} \mathrm{DW}\right)\end{array}$ & $\begin{array}{c}\text { FRAP } \\
\left(\mu \mathrm{mol} \mathrm{TE} \cdot \mathrm{g}^{-1} \mathrm{DW}\right)\end{array}$ \\
\hline Beauregard & \multirow{3}{*}{ Raw flesh } & $1.42 \pm 0.18$ & $1.35 \pm 0.01$ & $3.15 \pm 0.40$ \\
\hline O’Henry & & $0.53 \pm 0.03$ & $0.70 \pm 0.02$ & $1.50 \pm 0.05$ \\
\hline 414-purple & & $5.60 \pm 0.13$ & $2.98 \pm 0.04$ & $8.21 \pm 0.05$ \\
\hline O’Henry & \multirow[t]{2}{*}{ Raw peel } & $1.68 \pm 0.17$ & $4.80 \pm 0.04$ & $15.90 \pm 0.59$ \\
\hline 414-purple & & $7.03 \pm 0.07$ & $7.00 \pm 0.03$ & $29.99 \pm 0.06$ \\
\hline Beauregard & \multirow[b]{2}{*}{ Microwaving } & $1.45 \pm 0.11$ & $2.53 \pm 0.03$ & $7.42 \pm 0.28$ \\
\hline O’Henry & & $3.32 \pm 0.18$ & $2.35 \pm 0.02$ & $6.55 \pm 0.23$ \\
\hline 414-purple & Steaming & $11.84 \pm 0.09$ & $4.51 \pm 0.01$ & $19.57 \pm 0.09$ \\
\hline Beauregard & \multirow{3}{*}{ Baking } & $8.01 \pm 0.17$ & $2.52 \pm 0.01$ & $6.47 \pm 0.32$ \\
\hline O’Henry & & $3.55 \pm 0.20$ & $2.22 \pm 0.02$ & $6.20 \pm 0.11$ \\
\hline 414-purple & & $28.04 \pm 0.09$ & $2.44 \pm 0.00$ & $10.73 \pm 0.09$ \\
\hline
\end{tabular}

Legend: TPC - Total polyphenol content, GAE - gallic acid equivalent, DW - dry weight, DPPH - 2,2'-diphenyl-1-picrylhydrazyl, TE - Trolox equivalents, FRAP - Ferric reducing antioxidant power. The values are expressed as average \pm SD.

\section{Antioxidant activity}

The analysis of the antioxidant activity of natural products is the basis for the evaluation and recommendation of foods with high antioxidant activity to consumers (Xu et al., 2017). Antioxidant activity (AA) of sweet potatoes was determined by DPPH free radical scavenging activity and ferric reducing antioxidant power (FRAP) assay.
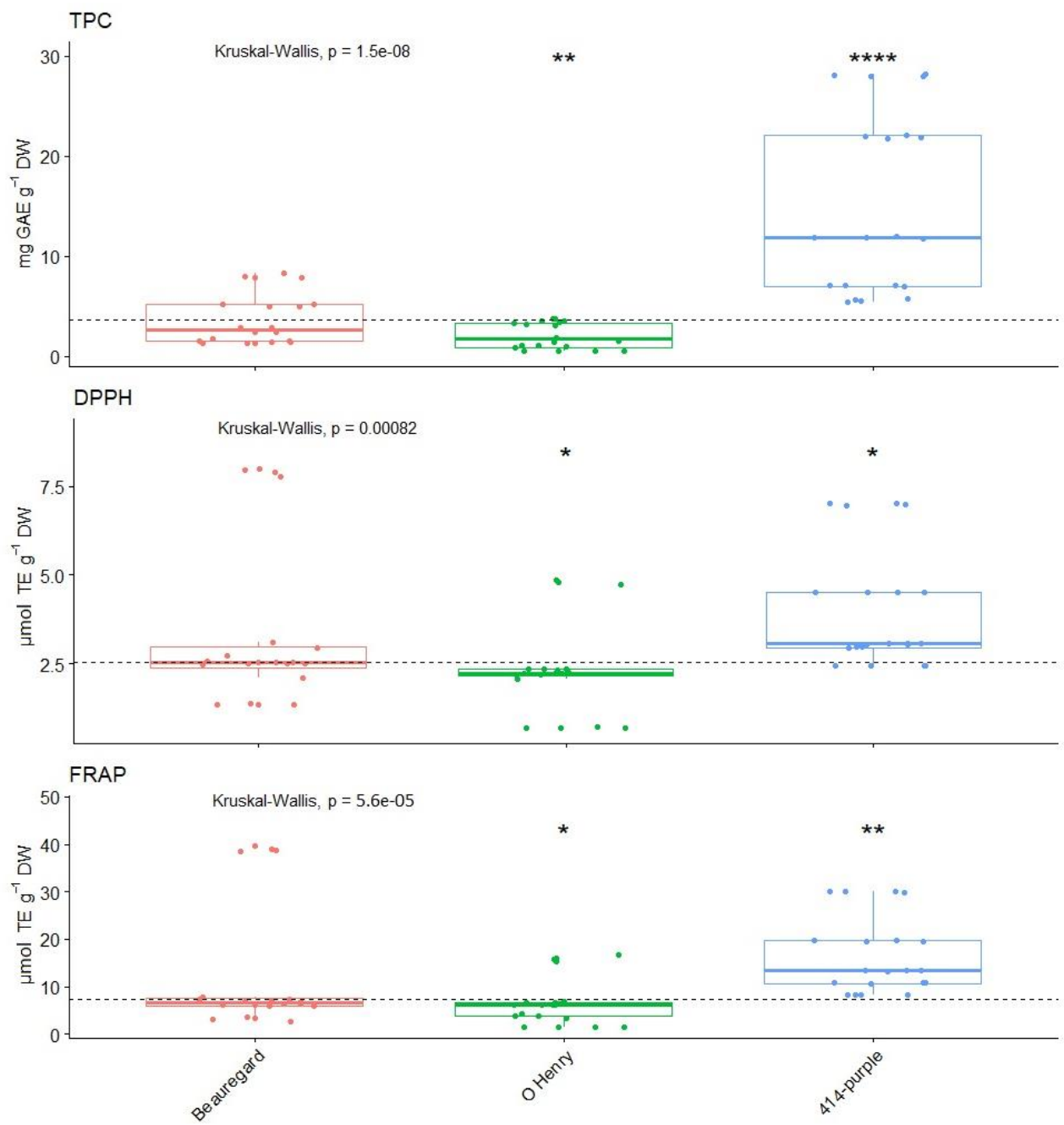

Figure 1 Statistical differences in total polyphenol content (TPC) and antioxidant activity (DPPH and FRAP) between monitored sweet potato varieties. The dashed line presents the average value for TPC, DPPH, and FRAP, separately. 


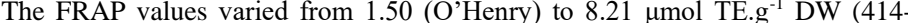
purple) in raw flesh and from 15.9 (O'Henry) to $39.0 \mu \mathrm{mol} \mathrm{TE.g}^{-1} \mathrm{DW}$ (Beauregard) in the raw peel. The antioxidant activity assessed by the DPPH method varied from 0.70 (O'Henry) to $2.98 \mu \mathrm{mol} \mathrm{TE.}^{-1} \mathrm{DW}$ (414-purple) in raw sweet potato flesh. By comparing individual parts (flesh and peel) of raw sweet potato, higher AA values were measured in the peel $\left(4.80 \mu \mathrm{mol} \mathrm{TE} . \mathrm{g}^{-1} \mathrm{DW}\right.$ in variety O'Henry $-7.91 \mu \mathrm{mol} \mathrm{TE} . \mathrm{g}^{-1} \mathrm{DW}$ in variety Beauregard) (Table 1). Among the monitored varieties, the highest AA was detected in the purple variety (414purple), which corresponds to the results of previous studies, which also show the highest antioxidant activity in purple-fleshed varieties compared to white and orange-fleshed (Teow et al., 2007; Padda et al., 2008; Donado-Pestana et al., 2012; Cartier et al., 2017). The presence of anthocyanins in purple SP varieties may result in higher AA compared to white or orange-fleshed sweet potato varieties (Oki et al., 2002). In variety Beauregard, the average AA in raw flesh was $1.35 \mu \mathrm{mol} \mathrm{TE} . \mathrm{g}^{-1} \mathrm{DW}$. This result is comparable to Ateea et al. (2012), which reports $1.72 \mu \mathrm{mol} \mathrm{TE} . \mathrm{g}^{-1} \mathrm{DW}$ (raw flesh - Beauregard). The antioxidant activity in white-fleshed SP from Nigeria was 0.23 and $0.26 \mu$ mol TE. $\mathrm{g}^{-1} \mathrm{DW}$ in raw flesh and raw peel, respectively (Salawu $\boldsymbol{e}$ t al., 2015). In contrast, higher AA was detected in Beauregard and O'Henry varieties from Virginia (11.8 and $3.17 \mu \mathrm{mol}$ TE. ${ }^{-1}$ DW) (Cartier et al., 2017).

Regarding antioxidant activity, there is a strong significant difference between varieties in DPPH $\left(\mathrm{p}=8.2 \mathrm{e}^{-04}\right)$ and FRAP $\left(\mathrm{p}=5.6 \mathrm{e}^{-05}\right)$ (Figure 1). The highest antioxidant activity evaluated by both methods, DPPH and FRAP, was found in variety 414-purple. Kruskal-Wallis test showed a strong dependence of antioxidant activity on sweet potato variety.

In heat-treated sweet potatoes, antioxidant activity evaluated by DPPH assay

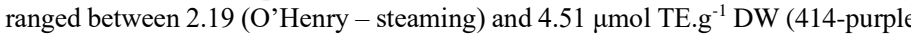
- steaming). The antioxidant activity of sweet potatoes increased due to heat treatments; a decrease of AA compared to raw flesh was observed only in 414purple variety after baking $\left(2.44 \mu \mathrm{mol} \mathrm{TE} . \mathrm{g}^{-1} \mathrm{DW}\right)$. Antioxidant activity in individual varieties of sweet potatoes assessed by DPPH increased in the following
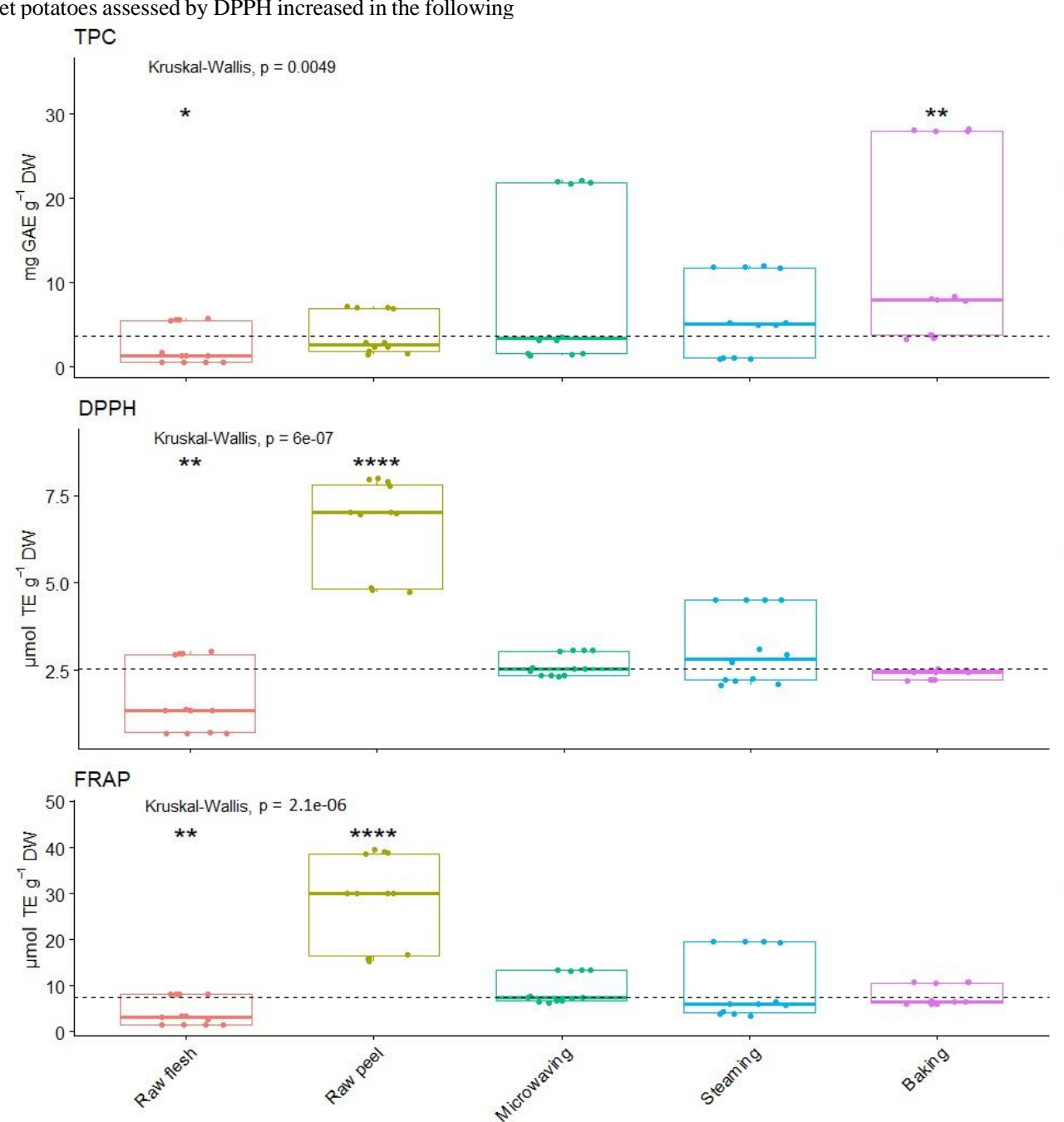

Figure 2 Statistical differences in total polyphenol content (TPC) and antioxidant activity (DPPH and FRAP) between heat treatment methods of sweet potatoes. The dashed line presents the average value for TPC, DPPH, and FRAP, separately. order: raw flesh < baking < microwaving $<$ steaming in variety Beauregard; raw flesh $<$ steaming $<$ baking $<$ microwaving in variety O'Henry; baking $<$ raw flesh $<$ microwaving < steaming in variety 414-purple. An increase of AA due to heat treatment was also reported previously (Ateea et al., 2012; Nicoletto et al., 2018;

Xu et al., 2018). This phenomenon has already been reported in many other vegetables, such as spinach, broccoli, peppers, etc. (Turkmen et al., 2005). In boiled and microwaved samples of Beauregard SP, Ateea et al. (2012) detected up to 3.70 and 3.50 -fold increase of AA compared to the raw sample. This fact may be the result of the destruction of complex components in sweet potatoes by heat (Kim et al., 2019). Newly generated substances during heat treatment may contribute to the increase of AA of sweet potatoes (Kourouma et al., 2019). In varieties Beauregard and 414-purple, the highest AA was detected in steamed samples. Moreover, Xu et al. (2018) reported the highest increase of AA in variety Beauregard and purple variety (Purple) after steaming compared to other hea treatments. The increase of antioxidant activity after heat treatment can be a result of the release of phenolic compounds due to the breakdown of cell structures by heat. The heat releases enzymes that cleave antioxidants, temperatures above 80 ${ }^{\circ} \mathrm{C}$ deactivate these enzymes, which prevents the loss of phenolic compounds (Minatel et al., 2017). The level of increase of AA after heat treatment is also affected by SP variety (Xu et al., 2018).

Statistical analysis confirmed the differences $(\mathrm{p}<0.05)$ between heat treatment methods/individual morphological parts of SP (raw flesh and raw peel) in all investigated parameters (TPC, DPPH, and FRAP) (Figure 2). Regarding individua morphological parts of sweet potato, peel showed statistically higher antioxidant activity (DPPH and FRAP) than flesh. Considering heat processing, no significan difference was found in antioxidant activity between investigated heat treatmen methods. From Figure 2, we can conclude that statistically higher TPC was observed in baked sweet potato samples. All obtained data were statistically confirmed. 


\section{Spearman's correlation test}

Spearman's correlation coefficient was used to determine relationships between monitored parameters - total polyphenol content and antioxidant activity (DPPH and FRAP) (Figure 3).

According to our results, among all analyzed parameters, positive correlations were observed. Phenolic compounds contribute most to the capability to scavenge DPPH free radicals, and thus, to the antioxidant activity of sweet potatoes (Cartier et al., 2017). The total polyphenol content in investigated sweet potato samples showed a positive relationship with antioxidant activity. TPC positively correlated with DPPH free radical scavenging activity $(r=0.43)$ and FRAP $(r=0.52)$. A very strong positive correlation was detected between both antioxidant activity methods - DPPH and FRAP $(r=0.89, \mathrm{p}<0.0001)$. Therefore, it can be suggested that both methods have comparable ability to predict the antioxidant activity of sweet potatoes.

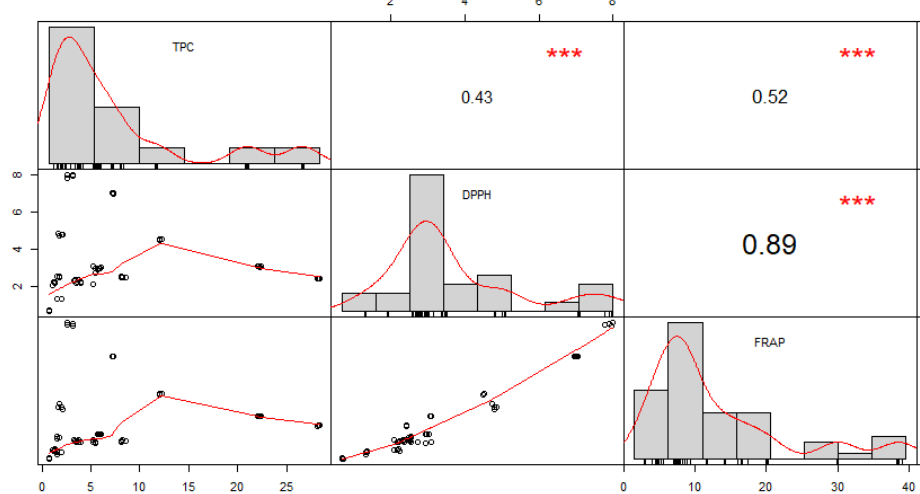

Figure 3 Correlations between total polyphenol content (TPC) and antioxidant activity (DPPH and FRAP).

\section{CONCLUSION}

The present study provides information on the content and the influence of hea treatment on polyphenols and antioxidant activity in three sweet potatoes varieties - Beauregard, O'Henry, and 414-purple. Overall, the highest content of polyphenols and antioxidant activity was observed in the purple-fleshed variety 414-purple. All studied processing methods positively affected the total polyphenol content and antioxidant activity in sweet potatoes. Statistical analysis confirmed the differences between the monitored varieties, as well as between the heat treatment methods.

Information provided by our study can bring a more complex knowledge of the processing impact on the content of bioactive compounds and the antioxidan activity of sweet potatoes.

Funding: This work was funded by projects VEGA 1/0722/19 and VEGA $1 / 0114 / 18$.

Acknowledgment: This publication was supported by the Operational program Integrated Infrastructure within the project: Demand-driven research for the sustainable and inovative food, Drive4SIFood 313011V336, cofinanced by the Euruopean Regional Development Fund.

We would also like to thank Ing. Darko Durica, PhD. (DespaD s.r.o.) for providing us samples for analysis.

\section{REFERENCES}

Arfaoui, L. (2021). Dietary Plant Polyphenols: Effects of Food Processing on Their Content and Bioavailability. Molecules, 26(10), 2959. https://doi.org/10.3390/molecules26102959

Ateea A, B., Omayma E, S., Mohammed M, Y., \& Ahmed MA El, G. (2012) Effect of home-cooking methods on phenolic composition and antioxidant activity of sweetpotato (Ipomoea batatas (L.) Lam.) cultivars grown in Egypt. Food and Nutrition Sciences, 2012. https://doi.org/10.4236/fns.2012.34069

Ayeleso, T. B., Ramachela, K., \& Mukwevho, E. (2016). A review of therapeutic potentials of sweet potato: pharmacological activities and influence of the cultivar. Tropical Journal of Pharmaceutical Research, 15(12), 2751-2761. https://doi.org/10.4314/tjpr.v15i12.31

Brand-Williams, W., Cuvelier, M. E., \& Berset, C. L. W. T. (1995). Use of a free radical method to evaluate antioxidant activity. LWT-Food Science and Technology, 28(1), 25-30. https://doi.org/10.1016/S0023-6438(95)80008-5

Cartier, A., Woods, J., Sismour, E., Allen, J., Ford, E., Githinji, L., \& Xu, Y. (2017). Physiochemical, nutritional and antioxidant properties of fourteen Virginia-grown sweet potato varieties. Journal of Food Measurement and Characterization, 11(3), 1333-1341. https://doi.org/10.1007/s11694-017-9511-8 de Albuquerque, T. M. R., Sampaio, K. B., \& de Souza, E. L. (2019). Sweet potato roots: Unrevealing an old food as a source of health promoting bioactive
compounds-A review. Trends in Food Science \& Technology, 85, 277-286 https://doi.org/10.1016/j.tifs.2018.11.006

Dincer, C., Karaoglan, M., Erden, F., Tetik, N., Topuz, A., \& Ozdemir, F. (2011) Effects of baking and boiling on the nutritional and antioxidant properties of sweet potato [Ipomoea batatas (L.) Lam.] cultivars. Plant Foods for Human Nutrition, 66(4), 341-347. https://doi.org/10.1007/s11130-011-0262-0

Donado-Pestana, C. M., Salgado, J. M., de Oliveira Rios, A., dos Santos, P. R., \& Jablonski, A. (2012). Stability of carotenoids, total phenolics and in vitro antioxidant capacity in the thermal processing of orange-fleshed sweet potato (Ipomoea batatas Lam.) cultivars grown in Brazil. Plant Foods for Human Nutrition, 67(3), 262-270. https://doi.org/10.1007/s11130-012-0298-9

Firuzi, O., Lacanna, A., Petrucci, R., Marrosu, G., \& Saso, L. (2005). Evaluation of the antioxidant activity of flavonoids by "ferric reducing antioxidant power" assay and cyclic voltammetry. Biochimica et Biophysica Acta (BBA)-General Subjects, 1721(1-3), 174-184. https://doi.org/10.1016/j.bbagen.2004.11.001

Guo, K., Liu, T., Xu, A., Zhang, L., Bian, X., Wei, C. (2019). Structural and functional properties of starches from root tubers of white, yellow, and purple $\begin{array}{llll}\text { sweet } \quad \text { potatoes. } & \text { Food } \quad \text { Hydrocolloids, } & 89, & 829-836 .\end{array}$ https://doi.org/10.1016/j.foodhyd.2018.11.058

Harrison, H. F., Mitchell, T. R., Peterson, J. K., Wechter, W. P., Majetich, G. F., $\&$ Snook, M. E. (2008). Contents of caffeoylquinic acid compounds in the storage roots of sixteen sweetpotato genotypes and their potential biological activity. Journal of the American Society for Horticultural Science, 133(4), 492-500. https://doi.org/10.21273/JASHS.133.4.492

Im, Y. R., Kim, I., \& Lee, J. (2021). Phenolic Composition and Antioxidant Activity of Purple Sweet Potato (Ipomoea batatas (L.) Lam.): Varieta Comparisons and Physical Distribution. Antioxidants, 10(3), 462 https://doi.org/10.3390/antiox10030462

Jain, P., Pandey, R., \& Shukla, S. S. (2015). Natural sources of anti-inflammation In Inflammation: Natural Resources and Its Applications (pp. 25-133). Springer, New Delhi.

Ji, H., Zhang, H., Li, H., \& Li, Y. (2015). Analysis on the nutrition composition and antioxidant activity of different types of sweet potato cultivars. Food and Nutrition Sciences, 6(01), 161. http://dx.doi.org/10.4236/fns.2015.61017

Jung, J. K., Lee, S. U., Kozukue, N., Levin, C. E., \& Friedman, M. (2011) Distribution of phenolic compounds and antioxidative activities in parts of sweet potato (Ipomoea batatas L.) plants and in home processed roots. Journal of Food Composition and Analysis, 24(1), 29-37. https://doi.org/10.1016/j.jfca.2010.03.025

Kim, D. C., Kim, C., \& In, M. J. (2015). Antioxidant activities of extracts prepared from sweet potatoes with different flesh colors. Journal of Applied Biological Chemistry, 58(1), 21-24. https://doi.org/10.3839/jabc.2015.005

Kim, M. Y., Lee, B. W., Lee, H. U., Lee, Y. Y., Kim, M. H., Lee, J. Y., ... \& Kim, H. J. (2019). Phenolic compounds and antioxidant activity in sweet potato after heat treatment. Journal of the Science of Food and Agriculture, 99(15), 6833 6840. https://doi.org/10.1002/jsfa.9968

Koala, M., Hema, A., Somé, K., Palé, E., Sérémé, A., Belem, J., \& Nacro, M (2013). Evaluation of eight orange fleshed sweetpotato (OFSP) varieties for their total antioxidant, total carotenoid and polyphenolic contents. Evaluation, 3(4), 67 73.

Kourouma, V., Mu, T. H., Zhang, M., \& Sun, H. N. (2020). Comparative study on chemical composition, polyphenols, flavonoids, carotenoids and antioxidant activities of various cultivars of sweet potato. International Journal of Food Science \& Technology, 55(1), 369-378. https://doi.org/10.1111/ijfs.14336

Kurata, R., Sun, H. N., Oki, T., Okuno, S., Ishiguro, K., \& Sugawara, T. (2019). Sweet potato polyphenols. In Sweet potato (pp. 177-222). Academic Press https://doi.org/10.1016/B978-0-12-813637-9.00007-7

Kwak, S. S. (2019). Biotechnology of the sweetpotato: ensuring global food and nutrition security in the face of climate change. Plant Cell Reports, 38, 1361-1363 https://doi.org/10.1007/s00299-019-02468-0

Lachman, J., Hamouz, K., Čepl, J., Pivec, V., Šulc, M., \& Dvořák, P. (2006). The effect of selected factors on polyphenol content and antioxidant activity in potato tubers. Chemické listy, 100(7).

Lim, T. K. (2016). Ipomoea batatas. In Edible Medicinal and Non-Medicinal Plants (pp. 92-171). Springer, Dordrecht.

Manach, C., Scalbert, A., Morand, C., Rémésy, C., \& Jiménez, L. (2004). Polyphenols: food sources and bioavailability. The American Journal of Clinical Nutrition, 79(5), 727-747. https://doi.org/10.1093/ajen/79.5.727

Minatel, I. O., Borges, C. V., Ferreira, M. I., Gomez, H. A. G., Chen, C. Y. O., \& Lima, G. P. P. (2017). Phenolic compounds: Functional properties, impact of processing and bioavailability. Phenolic Compd. Biol. Act, 8, 1-24. https://doi.org/10.5772/66368

Musilová, J., Bystrická, J., Árvay, J., \& Harangózo, L. (2017). Polyphenols and phenolic acids in sweet potato (Ipomoea batatas L.) roots. Potravinárstvo: Slovak Journal of Food Sciences, 11(1), 82-87. https://dx.doi.org/10.5219/705

Musilova, J., Lidikova, J., Vollmannova, A., Frankova, H., Urminska, D., Bojnanska, T., \& Toth, T. (2020). Influence of Heat Treatments on the Content of Bioactive Substances and Antioxidant Properties of Sweet Potato (Ipomoea batatas L.) Tubers. Journal of Food Quality, 2020 https://doi.org/10.1155/2020/8856260 
Mwanga, R. O., Andrade, M. I., Carey, E. E., Low, J. W., Yencho, G. C., \& Grüneberg, W. J. (2017). Sweetpotato (Ipomoea batatas L.). In Genetic improvement of tropical crops (pp. 181-218). Springer, Cham. https://doi.org/10.1007/978-3-319-59819-2 6

Nicoletto, C., Vianello, F., \& Sambo, P. (2018). Effect of different home-cooking methods on textural and nutritional properties of sweet potato genotypes grown in temperate climate conditions. Journal of the Science of Food and Agriculture, 98(2), 574-581. https://doi.org/10.1002/jsfa.8499

Oki, T., Masuda, M., Furuta, S., Nishiba, Y., Terahara, N., \& Suda, I. (2002). Involvement of anthocyanins and other phenolic compounds in radical-scavenging activity of purple-fleshed sweet potato cultivars. Journal of Food Science, 67(5), 1752-1756. https://doi.org/10.1111/j.1365-2621.2002.tb08718.x

Oki, T., Osame, M., Masuda, M., Kobayashi, M., Furuta, S., Nishiba, Y., ... \& Suda, I. (2003). Simple and rapid spectrophotometric method for selecting purplefleshed sweet potato cultivars with a high radical-scavenging activity. Breeding Science, 53(2), 101-107. https://doi.org/10.1270/jsbbs.53.101

Padda, M. S., \& Picha, D. H. (2008). Quantification of phenolic acids and antioxidant activity in sweetpotato genotypes. Scientia Horticulturae, 119(1), 17 20. https://doi.org/10.1016/j.scienta.2008.07.008

Padmaja, G. (2009). Uses and nutritional data of sweetpotato. In The Sweetpotato (pp. 189-234). Springer, Dordrecht. https://doi.org/10.1007/978-14020-9475-0_11

RStudio Team (2020). RStudio: Integrated Development for R. RStudio, PBC, Boston, MA. Available online: http://www.rstudio.com./

Rumbaoa, R. G. O., Cornago, D. F., \& Geronimo, I. M. (2009). Phenolic content and antioxidant capacity of Philippine sweet potato (Ipomoea batatas) varieties. Food Chemistry, 113(4)

https://doi.org/10.1016/j.foodchem.2008.08.088

Salawu, S. O., Udi, E., Akindahunsi, A. A., Boligon, A. A., \& Athayde, M. L. (2015). Antioxidant potential, phenolic profile and nutrient composition of flesh and peels from Nigerian white and purple skinned sweet potato (Ipomea batatas L.). Asian Journal of Plant Science and Research, 5(5), 14-23.

Siracusa, L., \& Ruberto, G. (2014). Plant polyphenol profiles as a tool for traceability and valuable support to biodiversity. In Polyphenols in plants (pp. 1533). Academic Press. https://doi.org/10.1016/B978-0-12-397934-6.00002-4

Sun, Y., Pan, Z., Yang, C., Jia, Z., \& Guo, X. (2019). Comparative assessment of phenolic profiles, cellular antioxidant and antiproliferative activities in ten varieties of sweet potato (Ipomoea batatas) storage roots. Molecules, 24(24), 4476. https://doi.org/10.3390/molecules24244476

Teow, C. C., Truong, V. D., McFeeters, R. F., Thompson, R. L., Pecota, K. V., \& Yencho, G. C. (2007). Antioxidant activities, phenolic and $\beta$-carotene contents of sweet potato genotypes with varying flesh colours. Food Chemistry, 103(3), 829838. https://doi.org/10.1016/j.foodchem.2006.09.033

Tian, J., Chen, J., Ye, X., \& Chen, S. (2016). Health benefits of the potato affected by domestic cooking: A review. Food Chemistry, 202, 165-175. https://doi.org/10.1016/j.foodchem.2016.01.120

Turkmen, N., Sari, F., \& Velioglu, Y. S. (2005). The effect of cooking methods on total phenolics and antioxidant activity of selected green vegetables. Food Chemistry, 93(4), 713-718. https://doi.org/10.1016/j.foodchem.2004.12.038

Wang, A., Li, R., Ren, L., Gao, X., Zhang, Y., Ma, Z., ... \& Luo, Y. (2018). A comparative metabolomics study of flavonoids in sweet potato with different flesh colors (Ipomoea batatas (L.) Lam). Food Chemistry, 260, 124-134. https://doi.org/10.1016/j.foodchem.2018.03.125

Xu, D. P., Li, Y., Meng, X., Zhou, T., Zhou, Y., Zheng, J., ... \& Li, H. B. (2017) Natural antioxidants in foods and medicinal plants: Extraction, assessment and resources. International Journal of Molecular Sciences, 18(1), 96. https://doi.org/10.3390/ijms18010096

Xu, Y., Cartier, A., Porter, A., Lalancette, K., Abraha-Eyob, Z., Sismour, E. N., ... \& Githinji, L. (2018). Bioactive compounds and biological activity of extracts from virginia-grown sweet potatoes affected by different cooking methods. Journal of Food Measurement and Characterization, 12(4), 2591-2597. https://doi.org/10.1007/s11694-018-9876-3 